\title{
DINÂMICA PRODUTIVA DA PECUÁRIA NA MESORREGIÃO OESTE CATARINENSE: ESPECIALIZAÇÃO E DIVERSIFICAÇÃO DA PRODUÇÃO NO PERÍODO DE 2000 A 2017
}

Eduardo von Dentz ${ }^{1}$ Carlos José Espíndola²

Resumo: $O$ processo de colonização da região Oeste catarinense, iniciado nas primeiras décadas do século XX, por meio da instalação de pequenos produtores mercantis, artesões, comerciantes, entre outros, promoveu, a partir da década de 1960, a emersão de diferentes agronegócios (carnes, leite, madeira, extrativismo, grãos). Esses agronegócios sofreram um intenso processo de reestruturação técnico-econômica, pós-anos de 1990, o que resultou em alterações geoeconômicas a jusante e a montante das atividades produtivas. Somente no que se refere à produção pecuária, em 2017, a mesorregião Oeste catarinense foi responsável por $51 \%$ da produção estadual de bovinos, $78 \%$ da produção catarinense de frangos, $79 \%$ da produção estadual de suínos e $75 \%$ da produção estadual de leite. Assim sendo, o objetivo do artigo é expor o desempenho produtivo dos agronegócios ligados à pecuária do Oeste catarinense entre os anos 2000-2017. Percebe-se ter havido um crescimento da produção dos principais agronegócios da pecuária, alinhado à concentração da produção e à diversificação dos produtos derivados, impulsionados pelo crescimento das exportações e do consumo interno. Metodologicamente seguiu-se os seguintes passos: levantamento bibliográfico, levantamento de dados, trabalhos técnicos e análise bibliográfica e dos dados.

Palavras-chave: Agronegócios. Especialização produtiva. Diversificação produtiva. Oeste catarinense.

\section{PRODUCTION DYNAMICS IN THE WESTERN MESOREGION CATARINENSE: PRODUCTION SPECIALIZATION AND DIVERSIFICATION IN THE PERIOD 2000 TO 2017}

Abstract: The Santa Catarina State Western region colonization process, initiated in the first decades of the twentieth century, through the installation of small mercantile producers, artisans, traders, among others, promoted from the 1960s the emersion of different agribusinesses (meat, milk, wood, extractivism, grains). These agribusinesses went through an intense technical and economic restructuring process, post-1990s, which resulted in geoeconomic productive activities changes downstream and upstream. With regard to livestock production, in 2017, the Santa Catarina's State West mesoregion accounted for $51 \%$ of state cattle production, $78 \%$ of state production of chickens, $79 \%$ of state pig production and $75 \%$ of state milk production. Thus, the article's objective is to expose the agribusinesses productive performance related to livestock farming in the West of Santa Catarina between the years 2000 to 2017. There has been an increase in the main livestock agribusinesses production, in line with the production concentration and the derivative products diversification, driven by the exports and domestic consumption

\footnotetext{
1 Universidade Federal de Santa Catarina, Departamento de Geociências, Florianópolis, Brasil, eduardovondentz@hotmail.com, https://orcid.org/0000-0002-0280-1149.

2 Universidade Federal de Santa Catarina, Departamento de Geociências, Florianópolis, Brasil, carlos.espindola@ufsc.br, https://orcid.org/0000-0002-5857-6067.
} 
growth. Methodologically, the following steps were taken: bibliographic survey, data collection, technical works, bibliographic analysis and data analysis.

Keywords: Agribusiness. Production specialization. Productive diversification. West of Santa Catarina.

\section{DINÁMICA PRODUCTIVA DE LA PECUARIA EN LA MESOREGIÓN OESTE CATARINENSE: ESPECIALIZACIÓN Y DIVERSIFICACIÓN DE LA PRODUCCIÓN EN EL PERÍODO DE 2000 A 2017}

Resumen: El proceso de colonización de la región Oeste catarinense, empezado en las primeras décadas del siglo XX, por medio de la instalación de pequeños productores mercantiles, artesanos, comerciantes, entre otros, promovió, después de la década de 1960, la emersión de distintos agronegocios (carnes, leche, madera, extractivismo, granos). Eses agronegocios sufrieron un intenso proceso de reestructuración técnico-económica, pasado años de 1990, lo que resultó en alteraciones geoeconómicas abajo y arriba de las actividades productivas. Solamente en lo que se refiere a la producción pecuaria, en 2017, la mesoregión Oeste catarinense fue responsable por $51 \%$ de la producción estadual de bovinos, $78 \%$ de la producción catarinense de pollos, $79 \%$ de la producción estadual de cerdos y $75 \%$ de la producción estadual de leche. Así siendo, el objetivo del artículo es exponer el desempeño productivo de los agronegocios ligados a la pecuaria del Oeste catarinense entre los años 2000-2017. Se percibe tener ocurrido un crecimiento de la producción de los principales agronegocios de la pecuaria, aliñado a la concentración de la producción y a la diversificación de los productos derivados, impulsados por lo crecimiento de las exportaciones y del consumo interno. Metodológicamente se siguió los siguientes pasos: levantamiento bibliográfico, levantamiento de datos, trabajos técnicos y análisis bibliográfica y de los datos.

Palabras clave: Agronegocio. Especialización productiva. Diversificación productiva. Oeste catarinense.

\section{Introdução}

A mesorregião Oeste de Santa Catarina, conforme demonstra o Mapa 1, é constituída por 118 municípios $^{3}$. Possui uma população de 1.210 .870 habitantes, o

\footnotetext{
${ }^{3}$ Compõem a mesorregião do Oeste Catarinense os municípios: Abelardo Luz, Água Doce, Águas de Chapecó, Águas Frias, Alto Bela Vista, Anchieta, Arabutã, Arroio Trinta, Arvoredo, Bandeirante, Barra Bonita, Belmonte, Bom Jesus, Bom Jesus do Oeste, Caçador, Caibi, Calmon, Campo Erê, Capinzal, Catanduvas, Caxambu do Sul, Chapecó, Concórdia, Cordilheira Alta, Coronel Freitas, Coronel Martins, Cunha Porã, Cunhataí, Descanso, Dionísio Cerqueira, Entre Rios, Erval Velho, Faxinal dos Guedes, Flor do Sertão, Formosa do Sul, Fraiburgo, Galvão, Guaraciaba, Guarujá do Sul, Guatambu, Herval d'Oeste, Ibiam, Ibicaré, lomerê, Ipira, Iporã do Oeste, Ipuaçu, Ipumirim, Iraceminha, Irani, Irati, Itá, Itapiranga, Jaborá, Jardinópolis, Joaçaba, Jupiá, Lacerdópolis, Lajeado Grande, Lebon Régis, Lindóia do Sul, Luzerna, Macieira, Maravilha, Marema, Matos Costa, Modelo, Mondaí, Nova Erechim, Nova Itaberaba, Novo Horizonte, Ouro, Ouro Verde, Paial, Palma Sola, Palmitos, Paraíso, Passos Maia, Peritiba, Pinhalzinho, Pinheiro Preto, Piratuba, Planalto Alegre, Ponte Serrada, Presidente Castelo Branco, Princesa, Quilombo, Rio das Antas, Riqueza, Romelândia, Saltinho, Salto Veloso, Santa Helena, Santa Terezinha do Progresso, Santiago do Sul, São Bernardino, São Carlos, São Domingos, São João do Oeste, São José do Cedro, São Lourenço do Oeste, São Miguel da Boa Vista, São Miguel do Oeste, Saudades, Seara, Serra Alta, Sul Brasil, Tangará, Tigrinhos, Treze Tílias, Tunápolis, União do Oeste, Vargeão, Vargem Bonita, Videira, Xanxerê, Xavantina e Xaxim.
} 
que representa aproximadamente $20 \%$ da população do estado de Santa Catarina. Desse total, cerca de 70\% residem nas cidades (IBGE, 2010).

\section{Mapa 1: Localização da mesorregião Oeste catarinense e suas principais cidades}

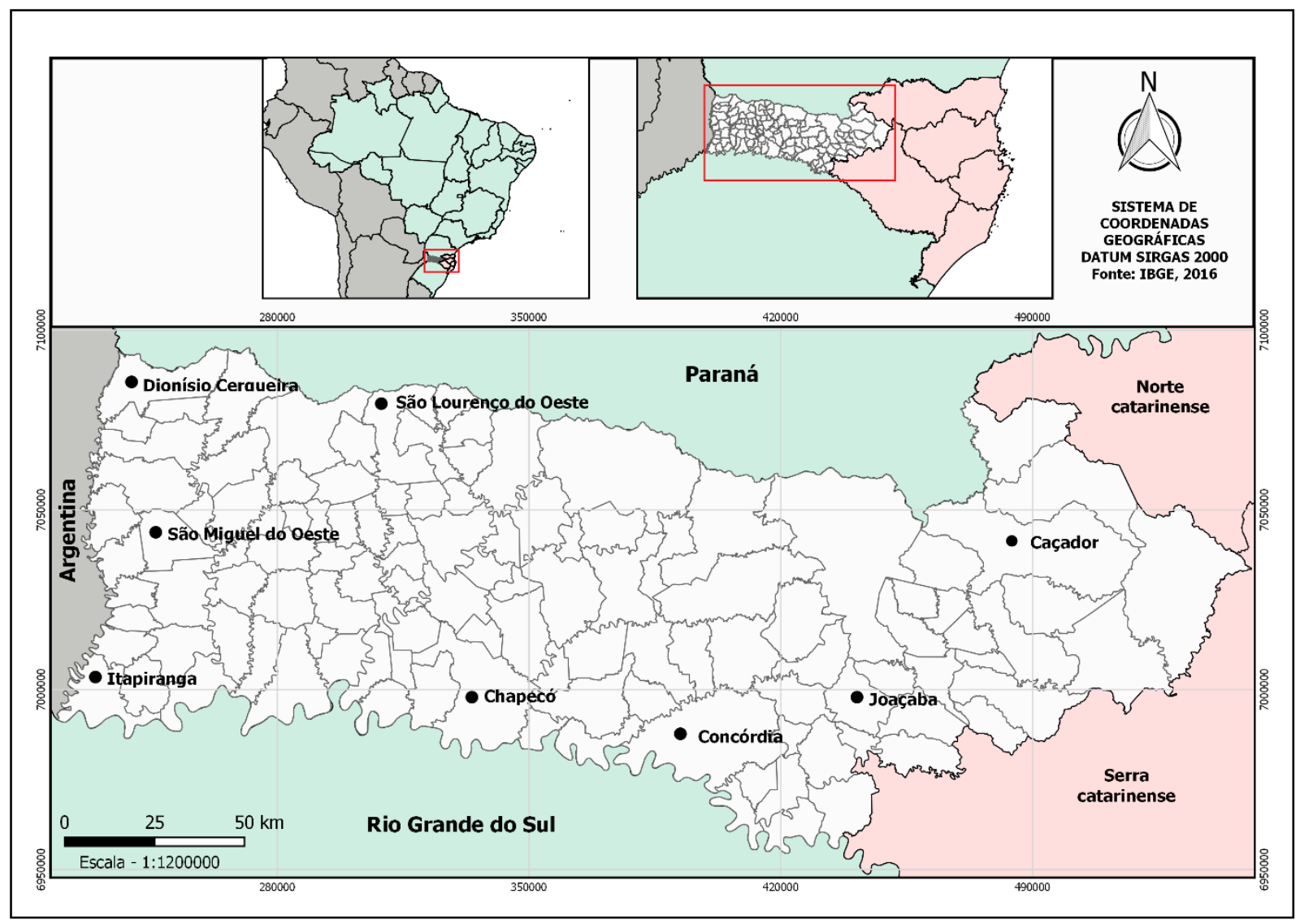

Fonte: Base cartográfica do IBGE. Elaborado pelos autores

Do ponto de vista econômico, a mesorregião Oeste catarinense foi responsável, em 2010, por 19,2\% do PIB catarinense, além de possuir uma renda per capita de aproximadamente $R \$ 20.500,00$, o que significa a terceira melhor renda per capita de Santa Catarina, considerando todas as mesorregiões, ficando atrás apenas do Norte catarinense e do Vale do Itajaí (IBGE, 2010).

O impulso, expansão e consolidação de diferentes agronegócios ${ }^{4}$, especialmente aqueles ligados à produção pecuária (bovino, suíno, frango e leite), fizeram com que uma nova dinâmica produtiva tenha se instalada no Oeste catarinense. Com isso, o progresso técnico ocorrido na pecuária resultou na

\footnotetext{
${ }^{4}$ Diferentemente de uma vasta bibliografia que define agronegócio apenas ao que está ligado à produção de commodities e ao tamanho da área produtiva, definem-se, aqui, os agronegócios como uma cadeia produtiva "que envolve desde a fabricação de insumos, passando pela produção nos estabelecimentos agropecuários, pela transformação e pelo seu consumo final" (CONTINI et al., 2006, p. 6).
} 
transformação do Oeste catarinense numa região com grande potencial produtivo de proteína animal. No que se refere à dinâmica recente da produção pecuária, a mesorregião Oeste catarinense, composta pelas microrregiões de Chapecó, Concórdia, Joaçaba, São Miguel do Oeste e Xanxerê, respondeu, em 2016, por $49,41 \%$ do rebanho de bovinos destinado ao abate ${ }^{5}$ no estado de Santa Catarina (EPAGRI/CEPA, 2017). Quando são incluídos nesse dado os abates para autoconsumo e comércio interestadual, a porcentagem sobe para $51,52 \%$ do total estadual (EPAGRI/CEPA, 2017). A produção de frangos do estado catarinense encontra-se fortemente concentrada na mesorregião Oeste, a qual, em 2016, foi responsável por 78\% da produção estadual (EPAGRI/CEPA, 2017).

De acordo com os dados levantados pela Cidasc, desses $78 \%$ produzidos, $22,86 \%$ concentram-se na microrregião de Joaçaba, 21,96\% na de Chapecó, $17,51 \%$ na de Concórdia e $8 \%$ na de Xanxerê. No total, em 2016, a mesorregião Oeste catarinense produziu mais de 896 milhões de frangos (EPAGRI/CEPA, 2017). Por outro lado, a síntese anual da Epagri/CEPA (2017) apresenta que a mesorregião Oeste catarinense, em 2016, foi responsável por 78,74\% dos suínos produzidos no estado. Além disso, as exportações de carne suína do estado de Santa Catarina passaram de 74,52 mil toneladas, em 2000, para 274,07 mil toneladas, em 2016. Em valores, o Ministério do Comércio Exterior assinala que, em 2000, Santa Catarina exportou 99,66 milhões de dólares em carne suína, atingindo 555,23 milhões de dólares nas exportações de 2016 (EPAGRI/CEPA, 2017).

Em termos de produção de leite, a mesorregião Oeste catarinense, em 2015, foi responsável por mais de $75 \%$ da produção de Santa Catarina. Em quantidade, produziu, em 2011, 1.846,7 milhão de litros, tendo atingido a marca de 2.299,5 milhões de litros de leite em 2015 (EPAGRI/CEPA, 2017). Portanto, o crescimento dos agronegócios ligados à pecuária em Santa Catarina é decorrente dos avanços na estrutura produtiva da mesorregião Oeste do estado. Assim sendo, diante desse dinamismo e da representatividade dos agronegócios de proteína animal, este artigo tem como objetivo expor o desempenho produtivo dos agronegócios ligados à pecuária do Oeste catarinense entre os anos 2000-2017.

Ao elaborar este texto, optou-se pela abordagem exploratória, que leva em conta o levantamento de informações referentes ao tema abordado, envolvendo levantamento bibliográfico e documental. Foram analisados artigos científicos, teses,

5 Consideram-se, no referido dado, os estabelecimentos que possuem o sistema de inspeção sanitária. 
dissertações e livros, de modo a avaliar e situar as produções científicas que dizem respeito à temática exposta. Ademais, operacionalmente, os dados estatísticos levantados são referentes aos relatórios de Produção Agrícola Municipal (PAM) e ao banco de dados do sistema SIDRA, acessados no Instituto Brasileiro de Geografia e Estatística (IBGE). Além disso, valeu-se das publicações anuais do Centro de Socioeconomia e Planejamento Agrícola da Epagri (EPAGRI/CEPA), dos levantamentos da Companhia Integrada de Desenvolvimento Agrícola de Santa Catarina (CIDASC), dos relatórios do Ministério da Agricultura, Pecuária e Abastecimento (MAPA) e dos relatórios técnicos do Ministério do Desenvolvimento da Indústria e do Comércio Exterior (MDIC). Neste sentido, além dessa introdução, o texto está dividido em três seções: primeiramente abordou-se o contexto histórico de colonização e as transformações ocorridas na agropecuária e na indústria do Oeste catarinense; na segunda seção abordou-se o desempenho produtivo dos principais agronegócios ligados à pecuária da mesorregião Oeste catarinense, considerando o período 2000 a 2017; por fim, na última seção, apresentam-se as considerações finais.

\section{Da Colonização às transformações ocorridas na agropecuária e na indústria do Oeste catarinense: uma síntese}

Diferentemente do planalto e da fachada atlântica, que tiveram o seu processo de ocupação entre os séculos XVII e XIX, a região Oeste foi efetivamente ocupada no início do século $X X^{6}$. Empresas de colonização multinacionais (Southern Brazil Lumber and Colonizations), nacionais (a Sociedade Territorial Mosele, Eberle, Ahrons e Cia.) e capitais comerciais de Porto Alegre (Bertaso), dentre outras, retalharam o Oeste catarinense em pequenos lotes de 20 a 30 ha, que foram

\footnotetext{
${ }^{6}$ De modo geral, do ponto de vista natural, o território de Santa Catarina pode ser caracterizado por apresentar um altiplano levemente inclinado na sua porção Oeste e uma área que se desdobra numa borda do planalto até o mar, na sua porção Leste (PELUSO Jr, 1990). A primeira etapa de ocupação do território catarinense é marcada por duas correntes de povoamento, começadas em meados do século XVII, com a chegada dos vicentistas paulistas entrando pelo Norte e indo em direção ao Sul do estado; e a outra corrente de ocupação ocorreu no planalto e deslocava-se para os campos meridionais. A segunda etapa de ocupação ocorreu no século XVIII, com a instalação de milhares de açorianos e madeirenses. Tratou-se da maior intervenção geopolítica e geoeconômica do governo de Portugal no Sul do Brasil (MAMIGONIAN, 1999). A terceira etapa de povoamento, ocorrida a partir dos anos 1820, refere-se às colônias de povoamento próximo de Rio Negro e São Pedro de Alcântara. Contudo, essas colônias se firmaram somente mais tarde, a partir de 1840. Outras colônias como a de Dona Francisca e a colônia Blumenau, no médio vale do rio Itajaí-Açu também se consolidaram nesse período. Ademais, essa terceira etapa de povoamento de Santa Catarina conta com as colônias italianas que se instalaram no Sul do estado na segunda metade do século XIX.
} 
vendidos, na sua grande parte, aos imigrantes italianos e alemães oriundos do Rio Grande do Sul (Espíndola, 1999).

Nesse sentido, Pertile (2008) salienta que, após o período de comercialização das terras, datado das duas primeiras décadas do século $X X$, intensificou-se, na região Oeste de Santa Catarina, a derrubada da mata. Essa atividade resultou no aproveitamento comercial da madeira exportada para outros países da América do Sul, principalmente para a Argentina. A exploração da madeira ocorria paralelamente à extração e comercialização da erva-mate. Esta, por sua vez, fazia parte da vegetação natural da região, com aproveitamento maior principalmente nos locais por onde passavam as tropas que levavam o gado do Rio Grande do Sul até São Paulo. Ademais, os estados do Paraná e Rio Grande do Sul, além da Argentina, eram importantes compradores da erva-mate catarinense durante as primeiras décadas do século XX. Portanto, a madeira e a erva-mate foram importantes produtos comerciais de Santa Catarina nesse período, conforme demonstraram Pertile (2008) e Campos (1987).

Entretanto, Espíndola (1999) chama a atenção para o fato de que, além dos ciclos da madeira e da erva-mate, se desenvolviam nas propriedades rurais plantações de feijão, trigo e mandioca, a criação de galinhas, porcos e outros animais, além de atividades artesanais. Manifestavam-se, desse modo, duas maneiras de existência da pequena produção, isto é, de um lado, as famílias especializavam-se num determinado bem que seria entregue ao comércio local/nacional e internacional; de outro, os pequenos produtores fabricavam seus instrumentos de trabalho, praticavam uma agricultura de subsistência (ESPÍNDOLA, 1999). À medida que aumentava a comercialização dos produtos agrícolas dessa região catarinense com as cidades do Rio de Janeiro e São Paulo, os produtores obtinham estímulos mercantis e meios necessários para a melhoria e ampliação de sua produção 7 .

A partir de 1950, essa estrutura assentada na pequena produção mercantil começa a passar por profundas transformações de ordem técnica e econômica. A primeira mudança decorre do papel desempenhado pela extensão rural que visava levar ao agricultor novas técnicas de produção e organização da propriedade, objetivando o aumento da produção e da produtividade. Esse processo amplia-se

\footnotetext{
7 Entre 1931-1935, as exportações de alfafa passaram de 6,9 milhões de quilos para 11,4 milhões, enquanto as exportações de milho cresceram de 2,5 milhões para 2,7 milhões. Outros produtos igualmente mostraram desempenhos favoráveis. Em 1937, enquanto as exportações de suínos para outros estados foram de 24.295 cabeças, as exportações de banha foram de 8.723 toneladas (BOSSLE, 1988).
} 
nos anos de 1960, com os financiamentos para compra de insumos, máquinas, e para formação de cooperativas e consolidação das agroindústrias formadas na região (Sadia, Perdigão, Chapecó, Seara, entre outras). A segunda transformação deriva da implantação, por parte da empresa Sadia, de um projeto de conquista de pequenos produtores capazes de desenvolver a criação de suínos ${ }^{8}$. A terceira decorre da introdução da avicultura na região, por parte do Grupo Sadia. A quarta refere-se à introdução de novas culturas, como por exemplo, a da soja e a da maçã ${ }^{9}$.

Em termos gerais, o processo de modernização da agricultura catarinense, apoiado pelas políticas de crédito subsidiado, política tecnológica e política fundiária, foi fundamental para criar um novo uso do tempo, um novo uso da terra e forjar o surgimento de diferentes agronegócios, que não mediram esforços no aumento da produção agropecuária, na ampliação dos ganhos de escala, na diversificação das atividades produtivas, etc. Com isso, emergiu uma geração de produtores que passaram a se orientar pela incorporação de sementes melhoradas geneticamente, melhoria das pastagens, no manejo zootécnico, nos confinamentos, na introdução de novos processos e produtos, etc. Em outras palavras, apoiaram-se na incorporação do progresso técnico, tanto a jusante quanto a montante do setor agropecuário (ESPÍNDOLA, 2016).

$\mathrm{Na}$ década de 1990, a abertura comercial, que eliminou a proteção aos setores do agronegócio, a sobrevalorização cambial, a redução de tarifas de importação de produtos agrícolas (MEDEIROS, 2009), a desnacionalização de diferentes segmentos do agronegócio e o fim do sistema de crédito agropecuário a partir de 1990 (LEITE, 1999), forçou os agronegócios do Oeste catarinense atuantes na produção de proteínas animais a um intenso processo de reestruturação técnicoeconômica (ESPÍNDOLA, 2002). Dentre as principais reestruturações, destacam-se a

\footnotetext{
${ }^{8}$ Com esse projeto, dava-se início ao sistema de integração. O sistema de integração foi implantado em Concórdia, a partir dos anos 50 , pela empresa Sadia, e disseminado para outras áreas do território catarinense pela Secretaria da Agricultura, Associações Rurais e agroindústrias. O sistema consiste em uma relação contratual entre a agroindústria e o produtor, em que a empresa garante a compra de toda a produção, fornecendo ao produtor a assistência técnica e parte dos insumos. A adoção do sistema de integração faz parte do projeto de modernização da agricultura (GRAZIANO DA SILVA, 1998), com o objetivo explícito de aumento da produção, da produtividade agrícola, novas relações de produção, dissolução da estrutura produtiva rural autossuficiente, mediante a utilização de métodos, técnicas, equipamentos e insumos modernos. Quer dizer, aumento considerável da composição orgânica do capital (ESPÍNDOLA, 2002).

${ }^{9}$ Outras transformações ainda foram visíveis. Dentre elas, destacam-se a redução da população rural que, em 1960, de acordo com o IBGE, era de $75 \%$ do total; em 2000, dados do IBGE mostraram ser a população rural de $18 \%$ do total, no Oeste catarinense. Além disso, destacam-se o aumento da safra de grãos e da área plantada de diversas culturas (fumo, arroz, banana, alho, feijão, soja, milho, maçã, uva); o elevado crescimento da produtividade de algumas culturas, como a soja, o fumo, o milho; e a redução da produtividade da cultura do feijão.
} 
instalação de equipamentos automatizados para as áreas de abate, a adoção de insumos químicos nos processos de mistura e maturação, o lançamento de novos produtos com maior valor agregado, a diversificação dos investimentos, as alterações patrimoniais e a desverticalização de diversas atividades ${ }^{10}$.

As reestruturações fizeram-se ainda nas mudanças nos sistemas produtivos criatórios, na implantação e desenvolvimento de material genético que alteraram as etapas de alimentação e manejo, na redução do ciclo completo na suinocultura ${ }^{11} \mathrm{e}$ na adoção dos novos mecanismos de financiamento da produção (ESPÍNDOLA, 2017) ${ }^{12}$. Assim, tais transformações possibilitaram ao Oeste catarinense participar ativamente na divisão nacional e internacional do trabalho da produção de proteína animal. Entre 1990-200013, o efetivo de cabaças de frango cresceu de 51,4 milhões para 90,7 milhões; o de cabeças de suínos aumentou de 2,2 milhões para 3,8 milhões; o de cabeças de bovinos passou de 1,1 milhão para 1,3 milhão (IBGE, 1990; 2000). No mesmo período, a produção de leite em litros cresceu de 274,7 mil litros para 602,8 mil litros. Desse modo, em termos gerais, os anos de 1980 e, sobretudo, os de 1990, promoveram significativas alterações nos agronegócios de carnes e leite do Oeste catarinense. Esse processo teve continuidade nos anos pós-2000, redefinindo novas dinâmicas geoeconômicas. Com isso, parte-se para apresentação e análise do desempenho produtivo desses agronegócios no período recente, bem como os principais impactos desse desempenho causados no território.

\footnotetext{
10 As diversificações das atividades ocorreram na Cooperativa Aurora, que passou a investir na industrialização de sucos e na cadeia produtiva de leite (SOUZA, 2014). Os investimentos diversificaram-se ainda com a criação de várias agroindústrias familiares (MIOR, 2003). No que tange às mudanças patrimoniais, merecem destaque, em 2009, a Seara, que foi comprada pela Cargill, e, posteriormente, vendida para o grupo JBS. Já a Perdigão, nos anos de 1990, transferiu seu controle acionário para um fundo de pensão e, nos anos de 2009, funde-se com a Sadia, originando a Brasil Food (BRF) (ESPÍNDOLA, 2014).

${ }^{11}$ A Cooperativa Aurora, por exemplo, reduziu o número de integrados de suínos de 8.662, em 1990, para 5.947, em 1999; enquanto a Chapecó reduziu de 2.582 para 116. Já a Sadia diminuiu o número de integrados de suínos de 14.182 para 4.890, no mesmo período (GOULARTI FILHO, 2007). Dos 67 mil suinocultores existentes em 1980, restavam apenas 25 mil em 1995. Já em 2002, havia apenas 15 mil suinocultores (LINS; COLETTI, 2010). Na entrevista realizada com o Presidente da Associação Catarinense de Criadores de Suínos, verificou-se que atualmente existem 8 mil suinocultores, sendo apenas $15 \%$ deles independentes.

12 Dentre os instrumentos de financiamento, destacam-se: o Certificado de Mercadoria com Emissão de Garantia (CMG), a Cédula do Produto Rural (CPR), o Certificado de Depósito Agropecuário (CDA), o Warrant Agropecuário (WA), o Certificado de Direitos Creditórios do Agronegócio (CDCA), a Letra de Comércio Agrícola (LCA) e o Certificado de Recebíveis do Agronegócio (CRA). São esses instrumentos que possibilitaram aos agronegócios integrarem-se ao mercado de capitais no acesso ao crédito e ao moderno sistema financeiro nacional/mundial (GONÇALVES, 2005).

${ }^{13}$ Não foram apresentados dados anteriores a essa data pelo fato de, para as mesorregiões, o IBGE ter iniciado a contagem a partir de 1990.
} 


\section{Desempenho produtivo dos agronegócios ligados à pecuária da mesorregião Oeste catarinense $(2000-2017)^{14}$}

De acordo com os levantamentos realizados pelo IBGE - Produção Pecuária Municipal, no período de 2012 a 2016 -, o rebanho bovino no Brasil cresceu 3,29\%, variando de 211.28 milhões de cabeças para 212.22 milhões de cabeças. No mesmo período, no estado de Santa Catarina, o crescimento do rebanho bovino foi de $10,47 \%$, saindo de 4.073 milhões de cabeças para 4.5 milhões. Na mesorregião Oeste catarinense, considerando o mesmo período, o crescimento foi de $8,7 \%$, apresentando variação de 1.960 milhão para 2.149 milhões de cabeças. No caso da mesorregião Oeste catarinense, quando se considera o período 2000-2016, o crescimento do rebanho bovino foi de $38,7 \%$, variando de 1.324 milhão para 2.149 milhões de cabeças.

No que diz respeito ao rebanho de galinhas, dados do PPM/IBGE apontam que, em 2012, o Brasil possuía um rebanho de 213.230 milhões de cabeças, tendo alcançado a marca dos 242.767 milhões de cabeças em 2017, o que representa um crescimento de 12,16\% nesse período. Para o estado de Santa Catarina, em 2012 o rebanho de galinhas ${ }^{15}$ somava 16.977 milhões de cabeças, alcançando a marca de 17.198 milhões de cabeças em 2017, representando, no período, um crescimento de 1,28\%. Na mesorregião Oeste catarinense, os números mostram que, em 2012, o rebanho de galinhas somava 9.235 milhões de cabeças, tendo alcançado a marca dos 9.403 milhões de cabeças em 2017, significando que, nesse período, houve um aumento de $1,78 \%$ no rebanho de galinhas. Somente para a mesorregião Oeste catarinense, ao se considerar o período 2000-2017, o rebanho de galinhas foi de 7.565 milhões para 9.403 milhões de cabeças, representando um aumento de $25 \%$ no período sinalizado.

No que se refere ao rebanho de suínos, informações da PPM/IBGE apontam que, para o Brasil, em 2012, havia um rebanho de 38.795 milhões de cabeças, sendo que alcançou, em 2017, a marca de 41.099 milhões de cabeças, representando um crescimento de 5,6\% entre 2012 e 2017. Já no estado de Santa Catarina, os dados assinalam que, em 2012, o rebanho de suínos era de 7.480 milhões de cabeças, atingindo a marca de 8.091 milhões de cabeças em 2017,

\footnotetext{
${ }^{14}$ Como vem ocorrendo ao longo do artigo, será dada maior atenção aos dados que tratam de bovinos, suínos, frangos e leite.

15 Os dados do rebanho de galinhas para Santa Catarina e para a mesorregião Oeste catarinense incluem os frangos abatidos no referido estado $(97,31 \%)$ e aqueles abatidos em outras UFs $(2,69 \%)$, bem como as diversas categorias de galinhas destinadas ao abate no período (bisavós, avós, matrizes, poedeiras comerciais e frangos de corte) (Cidasc, 2018).
} 
tendo apresentado nesse período um crescimento de 7,55\%. Na mesorregião Oeste catarinense, em 2012, o rebanho suíno somava 5.475 milhões de cabeças, alcançando 6.145 milhões de cabeças em 2017, o que representa um aumento de 10,9\%. Ao se levar em consideração o período 2000-2017, apenas para a mesorregião Oeste catarinense, o rebanho vai de 3.788 milhões de cabeças para 6.145 milhões de cabeças, um crescimento de $61,6 \%$.

Nesse sentido, dado os efetivos de rebanhos, o Gráfico 1 aponta para 0 desempenho produtivo em Valor Bruto de Produção (VBP) de bovinos, suínos, frangos e leite, todos da mesorregião Oeste catarinense. $O$ gráfico mostra que 0 agronegócio de frangos é o que movimenta maior valor da produção, tendo atingido quase 5 bilhões de reais em 2017. Em seguida, aparece o agronegócio de suínos, que movimentou em 2017 mais de 4 bilhões de reais. Na sequência, aparece o agronegócio de leite, que movimentou em 2017 mais de 2,5 bilhões de reais. Por último, o gráfico deixa claro que o agronegócio de bovinos movimentou, na região em tela, mais de 700 milhões de reais em 2017. Em termos de desempenho ao longo do período 2013-2017, todos apresentaram crescimento no VBP; o agronegócio de bovinos foi o que menos cresceu, e os agronegócios de suíno, leite e frango acenderam de modo semelhante entre eles ao longo do período (Gráfico 1). 


\section{Gráfico 1: Valor Bruto da Produção (VBP) - bovinos, leite, suínos e frangos -} da mesorregião Oeste catarinense de 2013 a $2017^{16}$

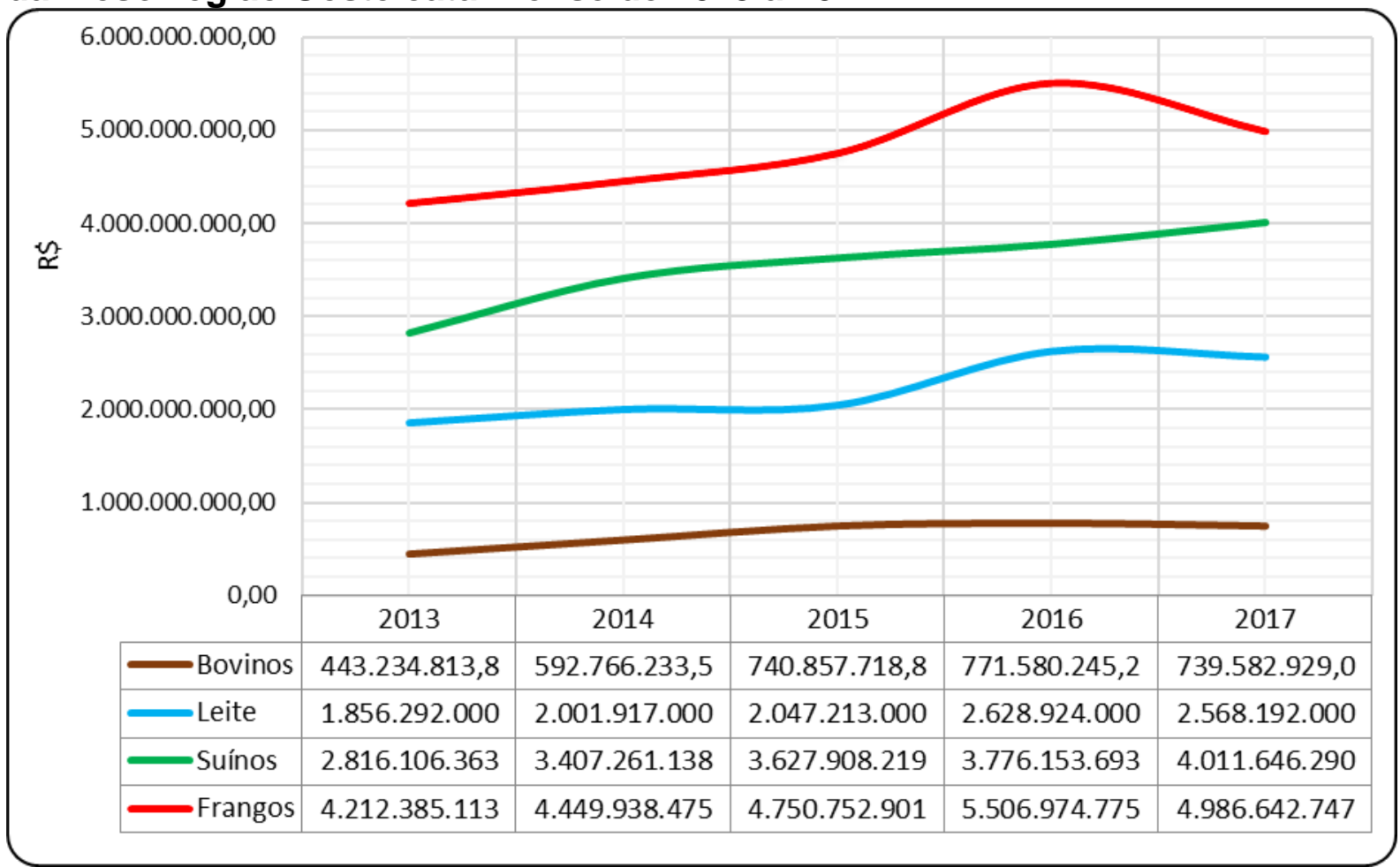

Fonte: Epagri/Cepa, 2017. Elaboração dos autores.

Contudo, vale salientar que o Gráfico 1 aponta para uma estagnação do VBP bovino de 2015 a 2017 e uma diminuição do VBP de frangos e leite de 2016 para 2017. Por outro lado, o VBP de suínos apresenta crescimento em todos os anos considerados no Gráfico 1. Aqui se buscará analisar as razões da queda do VBP e da produção do leite, especificamente, nos parágrafos seguintes, com auxílio dos dados dos Gráficos 2 e 3, tendo em conta as políticas comerciais adotadas pelo governo nos últimos dois anos.

A produção de leite na mesorregião Oeste catarinense tem crescido de maneira a quase quadruplicar em dezessete anos, vale dizer, de 2000 até 2017, como aponta o Gráfico 2. Em 2000, a produção de leite do Oeste catarinense foi de pouco mais de 600 milhões de litros, atingindo a marca que ultrapassou os 2,2 bilhões de litros em 2017, o que representa um aumento de aproximadamente $360 \%$ na produção leiteira. No entanto, vale assinalar, como aparece no Gráfico 2, que do ano de 2016 para o de 2017 foi o único período, tendo em conta o espaço de tempo apresentado no gráfico, em que houve diminuição do volume produzido. Enquanto em 2016 a mesorregião Oeste catarinense produziu 2,36 bilhões de litros, em 2017

16 O período analisado no gráfico não é maior em razão da inexistência dos dados. No período do gráfico 2013-2017, os números exatos foram conseguidos em trabalho de campo realizado em setembro de 2018 no Centro de Socioeconomia e Planejamento Agrícola da Epagri. 
foram produzidos 2,25 bilhões de litros, ou seja, trata-se de uma redução de 4,66\% na produção. Esse arrefecimento ocorreu em virtude da diminuição do número de produtores de leite na mesorregião, que, consequentemente, adveio por causa das políticas adotadas pelo governo visando à importação do produto em 2017, sobretudo do Uruguai e Argentina. Segundo reportagem apresentada no jornal Balde Branco (2017), no primeiro semestre de 2017, ocorreu a importação de grandes quantidades de leite; no mês de janeiro do referido ano, foram importados 152 milhões de litros de leite pelo Brasil.

Em decorrência dessas importações, o preço do leite recebido pelos produtores brasileiros apresentou queda, fazendo com que muitos produtores abandonassem as atividades ligadas à pecuária do leite, devido ao alto custo da produção e ao baixo valor recebido pelo produto. Segundo reportagem apresentada pelo Canal Rural (2018), nos meses de setembro e outubro de 2018, cerca de 45 produtores abandonaram a atividade leiteira por dia no Brasil. Nessa perspectiva, em caso de a política de governo não sofrer alterações, a tendência é que a quantidade de leite produzida em 2018 seja menor do que a obtida em 2017.

Gráfico 2: Produção de leite (em mil litros) na mesorregião Oeste catarinense (2000-2017).

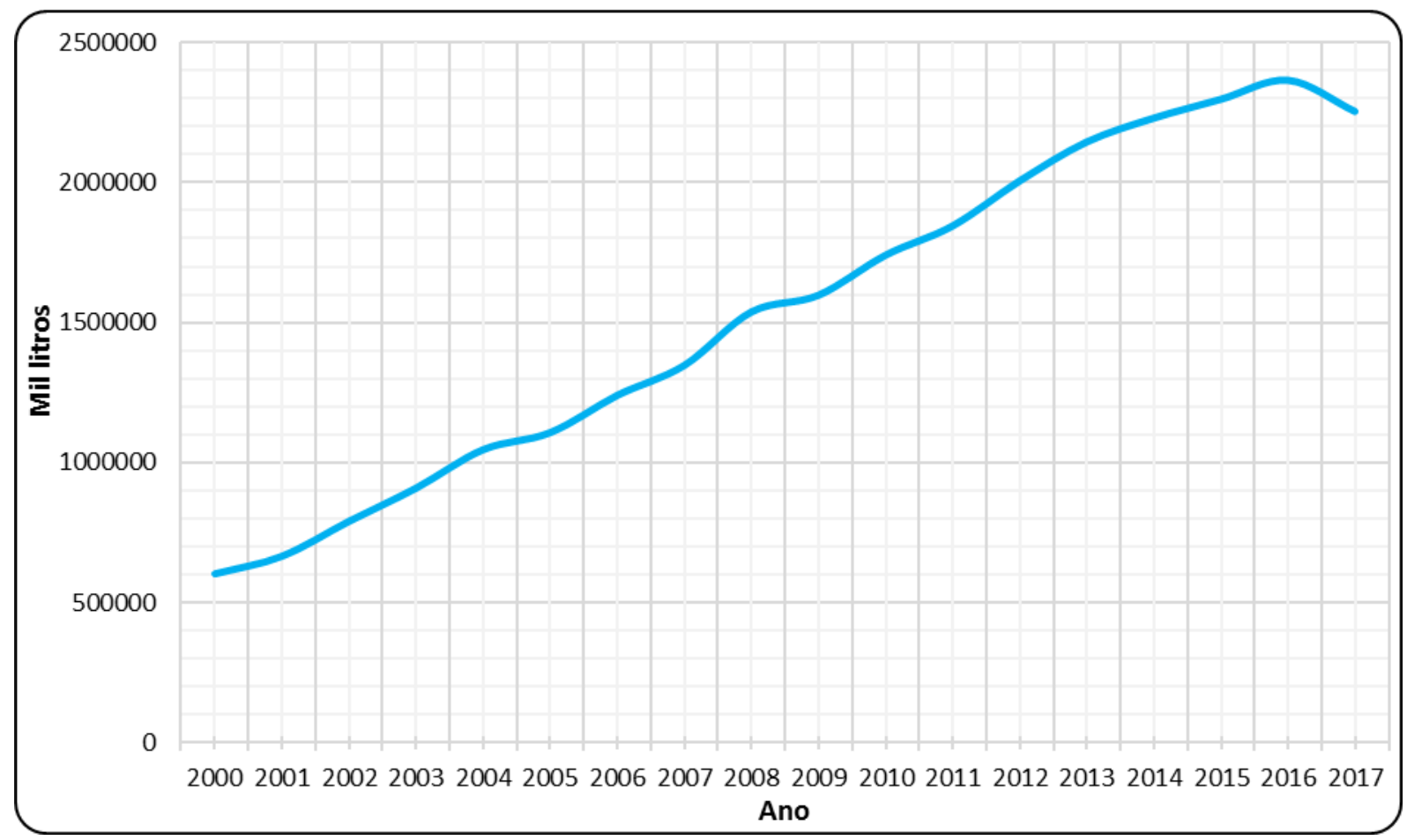

Fonte: IBGE/Produção Pecuária Municipal, 2017. 
Na mesma ótica, o Gráfico 3 confirma o que se demonstrou com o Gráfico 2, ou seja, houve um aumento consecutivo do número de vacas ordenhadas na mesorregião Oeste catarinense de 2000 (quase 323 mil vacas ordenhadas) até 2016 (mais de 751 mil vacas ordenhadas). No entanto, de 2016 para 2017, ocorreu uma queda de aproximadamente $29 \%$ no número de vacas ordenhadas, o que inevitavelmente resultou na diminuição da quantidade de leite produzida, tal como aparece no Gráfico 2.

Concomitantemente aos dados apresentados no Gráfico 2, podem-se usar as informações do Gráfico 3 para confirmar o fato de que é significativa a queda do número de produtores de leite na mesorregião em foco, haja vista que a diminuição no número de vacas ordenhadas e na produção foi decorrente do desestímulo das políticas governamentais voltadas para essa atividade produtiva. O governo optou por importar leite de outros países e, em detrimento disso, manter os ganhos reais dos produtores de leite do Oeste catarinense em baixa, o que, consequentemente, levou às desistências de produtores desse setor produtivo.

Essas políticas adotadas pelo governo, embora sejam positivas do ponto de vista da balança comercial, acabam deixando de lado políticas específicas que favoreçam internamente os pequenos produtores, como a manutenção do preço do produto, a disponibilização de programas de assistência técnica (inseminação, pastagem e desempenho produtivo das vacas) e assim por diante. Com isso, a lógica de organização individual dos produtores prevalece sobre a lógica de organização coletiva. Por outro lado, ainda que essa queda tenha ocorrido, a produtividade de leite por vaca tem melhorado, o que faz com que a mesorregião Oeste catarinense responda por cerca de $75 \%$ da produção de leite do estado de Santa Catarina e seja considerada uma das principais bacias leiteiras do Brasil. 


\section{Gráfico 3: Rebanho de vacas ordenhadas na mesorregião Oeste catarinense} (2000-2017)

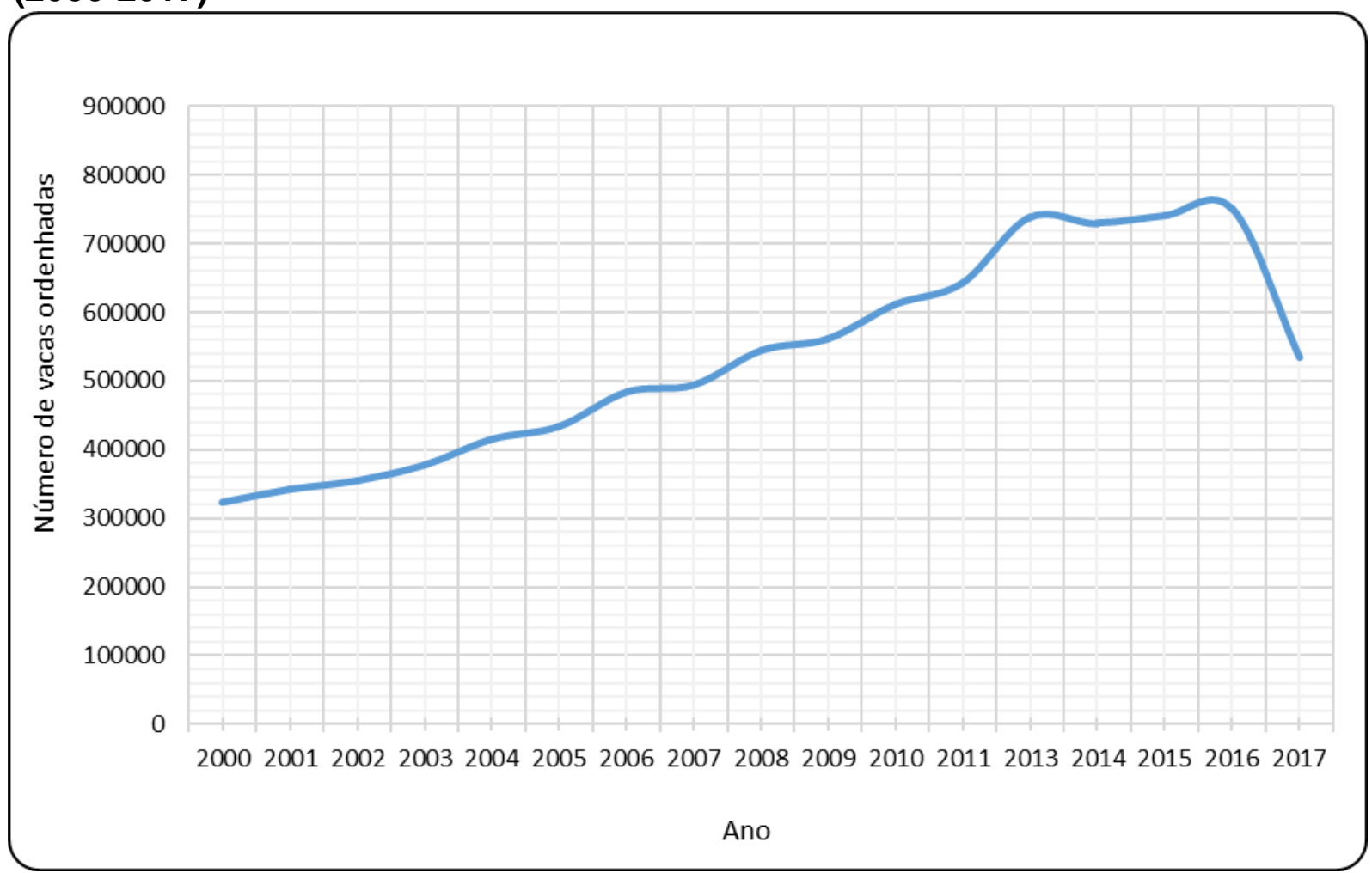

Fonte: IBGE/Produção Pecuária Municipal, 2017.

Com relação ao rebanho de bovinos e suínos, a mesorregião Oeste catarinense apresenta crescimento do número nos dois setores, como pode ser verificado no Gráfico 4. Ao longo dos dezessete anos, é possível perceber um crescimento contínuo do rebanho bovino, com uma leve queda de 2016 para 2017. Ao longo de todo o período do Gráfico 4, pode-se dizer que o rebanho bovino cresceu em torno de $65 \%$. Para o caso do rebanho suíno, não se pode apontar um crescimento contínuo, conquanto tenha ocorrido crescimento no rebanho. Houve uma estagnação do rebanho suíno no Oeste catarinense de 2001 a 2003, bem como de 2006 a 2007. Por outro lado, houve forte queda do efetivo de cabeças de suínos de 2009 a 2014, quando o rebanho volta a crescer. Esses períodos de estagnação e queda do número de cabeças de suínos se devem, em grande medida, ao embargo que países compradores da carne suína brasileira realizaram em alguns momentos. Essas interdições, em geral, são resultado das adequações na cadeia produtiva exigidas pelos países compradores da carne, detecção de inconsistência sanitária, dentre outras questões.

No entanto, mesmo que no período analisado tenham ocorrido estagnações e baixas no rebanho de suínos no Oeste catarinense, vale ressaltar que essa mesorregião é responsável por aproximadamente $75 \%$ da produção estadual de 
suínos. Desse modo, quando se leva em conta todo o período do Gráfico 4, pode-se afirmar que houve um aumento de $62 \%$ do rebanho suíno na mesorregião em destaque, comparando o número do ano 2000 com o de 2017.

\section{Gráfico 4: Rebanho de bovinos e suínos na mesorregião Oeste catarinense (2000-2017)}

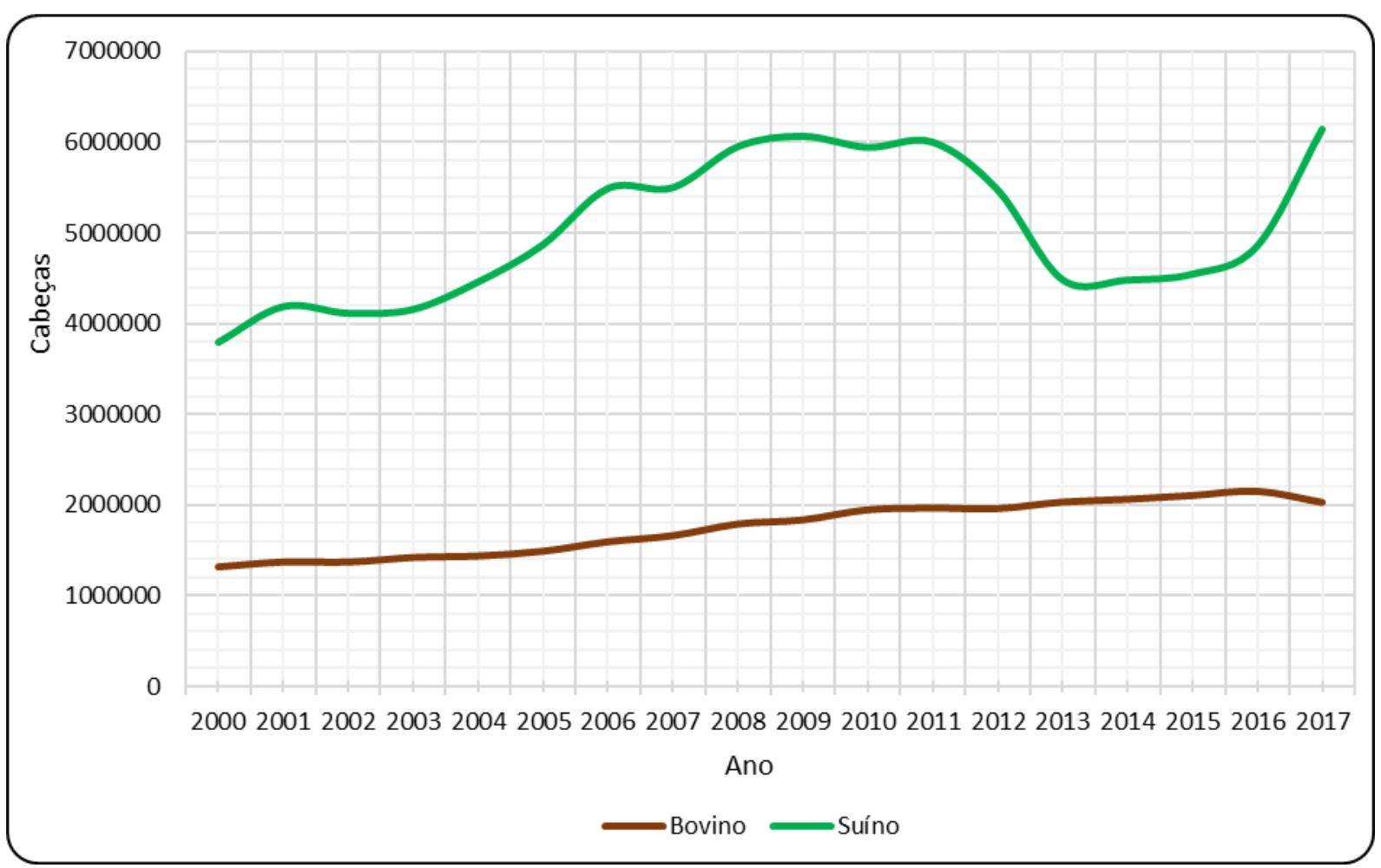

Fonte: IBGE/Produção Pecuária Municipal, 2017

Ademais, da mesma forma que foi citado para o caso do leite, na cadeia produtiva de suínos, muitos produtores vêm deixando de trabalhar com essa atividade em razão da inviabilidade econômica. Em outras palavras, o custo da produção é maior do que o valor obtido na venda do produto. Esse fato, porém, não necessariamente significa que a produção apresente queda, pois, na medida em que muitos produtores desistem da atividade, as grandes empresas do setor (Aurora, BRF, JBS, dentre outras) investem no aumento da produção concentrada em menor número de produtores (Espíndola, 1999) ${ }^{17}$. Assim sendo, o relatório da Associação Catarinense de Criadores de Suínos (ACCS) de 2010, levando em conta apenas os estabelecimentos registrados na mencionada Associação como produtores de reprodutores de suínos puros e cruzados, aponta que, em 1975, havia 162

\footnotetext{
17 De acordo com o censo agropecuário de 2017, na mesorregião Oeste catarinense existem 40.350 produtores de suínos. Em virtude da indisponibilidade dos dados, não foi possível identificar o número de produtores de suínos em censos agropecuários anteriores.
} 
estabelecimentos registrados, os quais respondiam por um total de 10.307 matrizes e por uma média de 64 matrizes por estabelecimento. Em 2010, o número de estabelecimentos caiu para sessenta, tendo o número de matrizes crescido para 49.631, e o número médio de matrizes por estabelecimento, para 828. Ou seja, trata-se da concentração de produção de suínos em um número significativamente reduzido de produtores, se comparado a períodos anteriores.

No que se refere ao rebanho de frangos, que o IBGE classifica como total de galináceos, no Gráfico 5 observa-se que, no período 2000-2017, houve um crescimento no número de animais. Contudo, não se tratou de um crescimento constante. De 2005 para 2006, houve queda no número do rebanho, assim como de 2007 para 2008; de 2009 para 2010; de 2011 para 2013; e de 2014 para 2016. Depois do rebanho mais alto em 2007 (126.967.935 de frangos), o ano de 2015 foi o que apresentou menor rebanho de frangos na mesorregião, com pouco mais de 100 milhões de animais (Gráfico 5).

\section{Gráfico 5: Rebanho de frangos na mesorregião Oeste catarinense (2000-2017)}

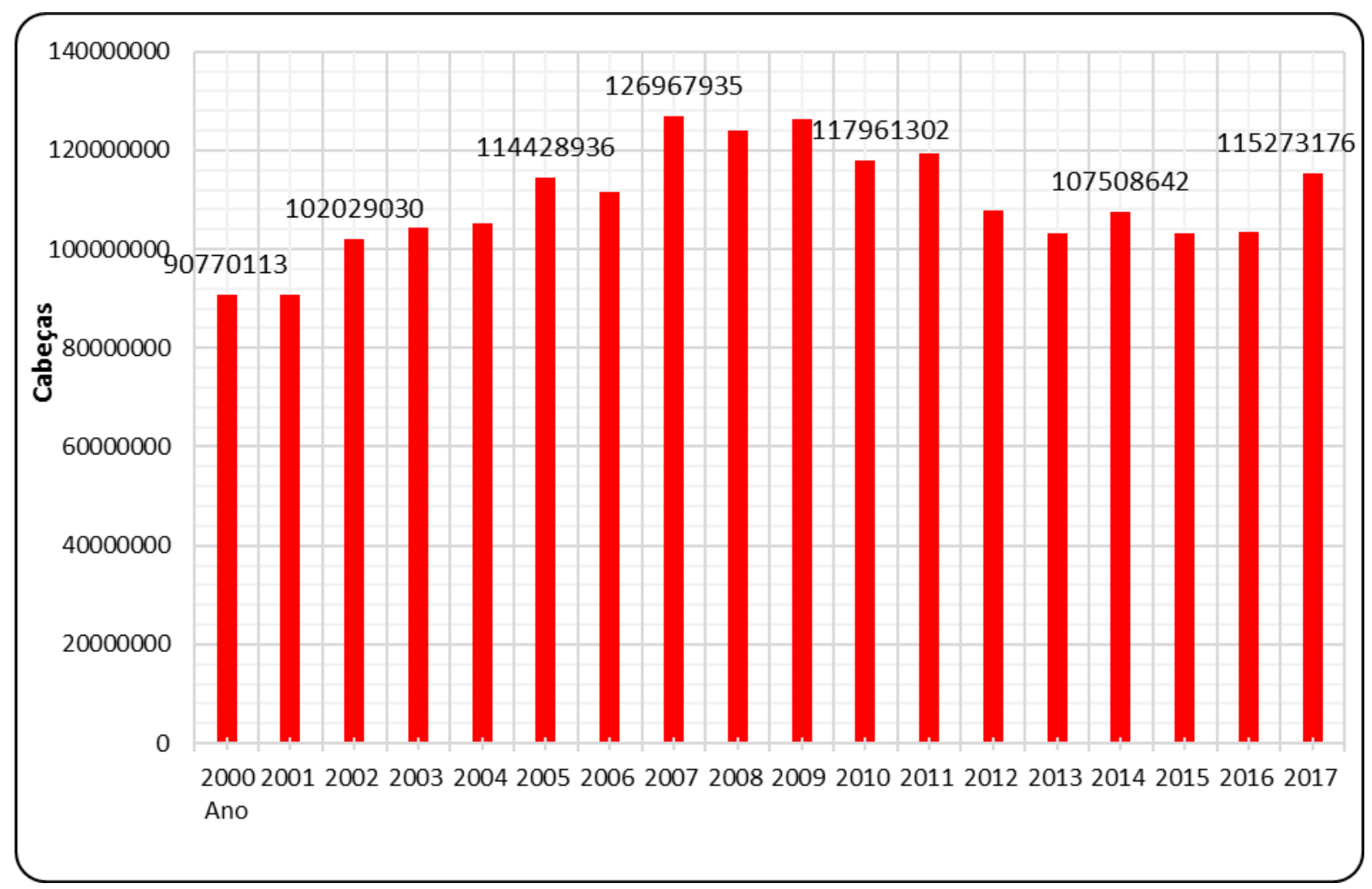

Fonte: IBGE/Produção Pecuária Municipal.

Considerando o todo do período analisado no Gráfico 5, pode-se afirmar que houve um aumento de $21,2 \%$ no rebanho de frangos da mesorregião Oeste catarinense. Como apontado para os casos da produção de leite e suínos, que juntamente com a cadeia de frangos são os mais expressivos agronegócios de 
proteína animal do Oeste catarinense, é primordial frisar que houve impactos negativos na continuidade do aumento da produção, principalmente em 2015, 2016 e 2017. Esses impactos são decorrentes de uma série de fatores que vieram ao longo do tempo desmoralizando o potencial agroindustrial de todo o Brasil e, por consequência, da região aqui estudada. Trata-se, em alguma medida, de impactos negativos causados pela operação "carne fraca", da polícia federal, deflagrada em meados de 2017, a qual apontava para irregularidades no sistema produtivo do complexo agroindustrial, mais especificamente em grupos como, por exemplo, a BRF, Friboi, JBS. Com isso, muitos países interromperam a compra de diferentes tipos de carnes do Brasil, assim como foram demitidos funcionários e interditado o funcionamento de alguns frigoríficos isolados no interior do Brasil.

Dessa maneira, essa operação marcou negativamente o complexo agroindustrial de carnes no Brasil, o que fez cair a credibilidade do setor no exterior. No entanto, associado a esse fator, vale lembrar que, desde de 2015, as cadeias produtivas de frangos, bovinos, suínos e leite vêm sofrendo mudanças em virtude do encolhimento do mercado interno com a perda de poder de consumo das camadas sociais mais baixas, com a alta do desemprego e o marcante período de recessão. Por outro lado, externamente, como já comentado, o fechamento de alguns mercados, com países que historicamente foram importantes parceiros comerciais do Brasil, contribuiu para que o setor sofresse a turbulência apresentada nos Gráficos 3, 4 e 5. Além do citado, vale ressaltar que a baixa do preço recebido pelos produtores colaborou para que muitos deixassem de se dedicar à produção pecuária.

Contudo, esses embaraços ocorridos nos agronegócios de proteína animal estão longe de desmontar o complexo agroindustrial da pecuária no Brasil e no Oeste catarinense. Depois do processo de reestruturação técnico-produtiva pelo qual o setor passou nas últimas décadas, formou-se e consolidou-se, nesse setor, um dos mais importantes ramos da economia regional e nacional. No estado de Santa Catarina, por exemplo, a produção de leite, frangos e suínos está fortemente concentrada no Oeste do estado, em torno de $75 \%$, o que faz da região uma referência na produção do setor. Ademais, de modo geral, o desempenho produtivo dos principais agronegócios ligados à pecuária na mesorregião Oeste catarinense apresentou crescimento no período que vai de 2000 até 2017, o que significa que esses agronegócios estão em processo de desenvolvimento. 
As críticas que foram feitas neste artigo servem para apontar questões que podem ser evitadas por um conjunto de pessoas e instituições que trabalham nesses setores, de modo a fazer com que o crescimento e os ganhos obtidos com base nesses agronegócios possam ser ainda maiores. Assim sendo, vale frisar que há, na mesorregião Oeste catarinense, cadeias produtivas nos agronegócios de leite, frangos, suínos e bovinos consolidadas e muito fortes, que cooperam significativamente para o desenvolvimento social e econômico da região. Inerente a isso, as mudanças em tais cadeias produtivas vão ocorrendo na medida em que 0 modo capitalista de produção vai impondo novas regras.

\section{Considerações Finais}

A gênese da produção pecuária da mesorregião Oeste catarinense, sobretudo no que se refere aos agronegócios de frangos, bovinos, suínos e leite, é decorrente de um processo histórico ligado à ocupação e ao desenvolvimento social e econômico da região. Trata-se de uma região na qual predominou a ocupação em pequenos lotes de grupos familiares. Esses lotes foram vendidos aos colonos oriundos do Rio Grande do Sul por empresas colonizadoras que se instalaram no local no início do século XX. Dessa forma, a extração e comércio da madeira e da erva-mate nas primeiras décadas do século $X X$ foram importantes atividades que serviram para capitalizar os agricultores da região a investirem em outras atividades, cita-se, especialmente, aquelas ligadas à agricultura e pecuária. Assim, em meados de 1940, teve início na região um processo de venda do excedente produzido, de modo a se obter uma renda extra para, dentre outras questões, o melhoramento técnico das atividades ligadas à pecuária local.

A partir da segunda metade do século $X X$, as mudanças que modernizaram o setor agropecuário fizeram com que grupos empresariais com capacidade de transformar a produção pecuária se instalassem na região, para comprar dos produtores a matéria-prima que deu origem a uma diversidade de produtos derivados da produção de frangos, leite, suínos e bovinos. Nesse sentido, alguns grandes grupos empresariais voltados a esse setor se instalaram, consolidaram-se e se expandiram para outras partes do Brasil a partir dos negócios iniciados no Oeste catarinense. Nas décadas de 1980 e 1990, a agropecuária da região passou por um intenso processo de reestruturação técnico-econômica, que serviu de base para o aumento da produção pecuária desde essa época. Por tais razões, a mesorregião 
Oeste catarinense desponta, em cenário estadual, nacional e mundial, como uma das principais produtoras de frangos, leite, suínos e bovinos.

Houve, portanto, uma especialização produtiva desses agronegócios no Oeste catarinense, de modo que se tornaram atividades econômicas responsáveis por boa parte do dinamismo geoeconômico da região. Por outro lado, aconteceu uma diversificação produtiva derivada desses mesmos agronegócios, na medida em que foram criando-se diversos produtos que são desdobramentos desses agronegócios, como por exemplo, no caso do leite, a produção de iogurte, leite integral, leite desnatado, creme de leite, requeijão, queijo, leite condensado, creme de leite. Desse modo, consolidaram-se na mesorregião complexos agroindustriais com produção diversificada de produtos, mas centralizados nesses agronegócios.

Os dados apontados pela Epagri/Cepa (2017) mostram que o desempenho produtivo dos agronegócios ligados à pecuária (bovinos, suínos, frangos e leite) da mesorregião Oeste catarinense, levando em conta o Valor Bruto da Produção (VBP) do ano de 2017, faz dessa mesorregião a responsável por $51 \%$ da produção estadual de bovinos, $79 \%$ da de frangos, $78 \%$ da de suínos e $77 \%$ da de leite. Ademais, no que diz respeito aos rebanhos de bovinos, suínos, frangos e vacas leiteiras, observa-se um crescimento nos efetivos de rebanho em todos esses agronegócios, com destaque para a representatividade regional das vacas de leite, de suínos e de frangos. No entanto, sobretudo no que se refere à produção e ao rebanho de vacas de leite, suínos e frangos, notou-se uma queda, principalmente de 2016 para 2017. Isso ocorreu em virtude do enfraquecimento do poder de consumo do mercado interno, da desmoralização do setor de carnes pela operação "carne fraca" da polícia federal - o que refletiu na diminuição das exportações desses produtos - e na adoção de políticas governamentais voltadas para a importação, no caso do leite, o que representou a falta de incentivos aos produtores rurais para continuar a fomentar as atividades produtivas.

Portanto, alguns percalços fizeram com que o crescimento consecutivo de todos os agronegócios analisados neste artigo deixasse de ter uma continuidade nos anos de 2016 e 2017. O que, em nenhuma hipótese, representa que esses agronegócios da mesorregião Oeste catarinense deixaram de marcar fortemente 0 cenário social e econômico da região. Trata-se de agronegócios consolidados do ponto de vista produtivo e, por conseguinte, estrutural, mas que apresentam uma concentração da produção, uma especialização da produção e uma diversificação da produção, na condição de produtos que se originam nesses agronegócios. Essas 
constatações são, na verdade, resultados de um sistema agroindustrial em constante transformação, característico do capitalismo comercial consolidado ao longo do tempo na mesorregião em estudo.

\section{REFERÊNCIAS}

ACCS. Relatório da Associação dos Criadores Catarinenses de Suínos. Chapecó, 2010. Disponível em:

$<$ http://www.accs.org.br/arquivos internos/index.php?abrir=downloads\&acao=exibe tipo\&tip o=4 >. Acesso em: 19 nov. 2018.

BALDE BRANCO. Importação e competitividade do leite brasileiro. São Paulo, 2017. Disponível em: <http://www.baldebranco.com.br/importacao-e-competitividade-do-leitebrasileiro/>. Acesso em: 18 nov. 2018.

BOSSLE, Ondina Pereira. História da industrialização catarinense: das origens à integração no desenvolvimento brasileiro. 2. ed. Florianópolis: CNI/FIESC, 1988. 155p.

CAMPOS. Indio. Os colonos do Rio Uruguai: relação entre a pequena produção e a agroindústria no Oeste Catarinense. Campina Grande: UFPB, 1987. (Dissertação, Mestrado em Economia).

CANAL RURAL. Informações do mercado do leite. Porto Alegre, 2018. Disponível em: $<$ https://canalrural.uol.com.br/programas/informacao/mercado-e-cia/a-cada-24-horas-cercade-45-produtores-de-leite-abandonam-a-atividade/>. Acesso em: 19 nov. 2018.

CIDASC. Companhia Integrada de Desenvolvimento Agrícola de Santa Catarina.

Florianópolis, 2018. Disponível em: <www.cidasc.sc.gov.br/>. Acesso em: 15 out. 2018.

CONTINI, E. et al. Evolução recente e tendências do agronegócio. Revista de Política Agrícola, Brasília, CONAB, ano XV, n. 1, jan.-fev.-mar. 2006, p. 5-28. Disponível em: <https://seer.sede.embrapa.br/index.php/RPA/article/view/475>. Acesso em: 10 ago. 2018.

EPAGRI/CEPA. Centro de Socioeconomia e Planejamento Agrícola de Santa Catarina. Síntese Anual da Agricultura Catarinense, 2017. Disponível em: <http://www.epagri.sc.gov.br/?page id=3210>. Acesso em: 18 nov. 2018.

ESPÍNDOLA, C. J. As Agroindústrias no Brasil: o caso Sadia. Chapecó. Grifos, 1999.

ESPÍNDOLA, C. J. Tecnologia e as novas relações de trabalho nas agroindústrias de carne do sul do Brasil. Scripta Nova, Barcelona, v. 1, p. 89-113, 2002.

ESPÍNDOLA, C. J. A internacionalização do Agronegócio Brasileiro de Carnes: a trajetória da Brasil Foods In: Anais do VI Congresso Iberoamericano de Estudios Territoriales y Ambientais, São Paulo, 2014. p. 1866-1882.

ESPÍNDOLA, Carlos José. Ciclo de crescimento da economia brasileira e desempenho do agronegócio catarinense. Revista de Geografia (Londrina), v. 25, p. 91-109, 2016.

ESPÍNDOLA, Carlos José. As duas macroformações socioespaciais do Sul do Brasil na gênese da indústria de carnes. Ensaios FEE (online), v. 37, p. 715-738, 2016. Disponível em: <https://revistas.fee.tche.br/index.php/ensaios/article/viewFile/3419/3792>. Acesso em: 20. abr. 2017. 
ESPÍNDOLA, Carlos José. Estruturas e estratégias geoeconômicas: estudos de cadeias produtivas específicas. Jundiai: Pac editorial, 2017. v. 40. 222p.

GONÇALVES, José Sidnei. Agricultura sob a égide do capital financeiro: passo rumo ao aprofundamento do desenvolvimento dos agronegócios. Informações econômicas, São Paulo, IEA, v. 35, p. 7-36, abr. 2005.

GOULARTI FILHO, Alcides. Formação econômica de Santa Catarina. 3. ed. Florianópolis: Editora UFSC, 2016.

GRAZIANO DA SILVA, José. A nova dinâmica da agricultura brasileira. 2. ed. local: Unicamp, 1998.

IBGE. Censo Demográfico, 1960. Disponível em: $<$ https://biblioteca.ibge.gov.br/visualizacao/periodicos/68/cd 1960 v1 t15 p2 sc.pdf>. Acesso em: 24 set. 2018.

IBGE. Pesquisa Pecuária Municipal. Rio de Janeiro, 1990. Disponível em: <https://sidra.ibge.gov.br/tabela/3939\#resultado>. Acesso em: 30 nov. 2018.

IBGE. Pesquisa Pecuária Municipal. Rio de Janeiro. 2000. Disponível em: <https://sidra.ibge.gov.br/tabela/3939\#resultado>. Acesso em: 30 nov. 2018.

IBGE. Censo Demográfico, 2010. Disponível em: $<$ https://censo2010.ibge.gov.br/sinopse/index.php?uf=42\&dados=0 >. Acesso em: 25 ago. 2018.

IBGE. Pesquisa Pecuária Municipal. Rio de Janeiro, 2018. Disponível em:<https://sidra.ibge.gov.br/pesquisa/ppm/tabelas>. Acesso em: 16 nov. 2018.

LEITE, S. Políticas Públicas e agricultura no Brasil: comentários sobre o cenário recente. Petrópolis: Vozes, 1999.

LINS, H. N.; COLETTI, T. Globalização, agroindústria e agricultura Familiar: a recente saga do Oeste catarinense em torno da suinocultura. Anais do Encontro nacional de economia política, n. 15, 2010, São Luiz, 2010.

MAMIGONIAN, Armen. As conquistas marítimas portuguesas e a incorporação do litoral de Santa Catarina. In: O mundo que o português criou. Recife: CNPq/Fjn, 1999.

MEDEIROS, M. C. As mudanças no mercado consumidor de alimentos e a diversificação da oferta no setor agroalimentar brasileiro. Revista de Geografia Econômica (Florianópolis), v. 2, p. 20-41, 2009.

MIOR, Luiz Carlos. Agricultura familiar, agroindústria e território: a dinâmica das redes de desenvolvimento rural no Oeste catarinense. 2003. 316 f. Tese (Doutorado) - Curso de Interdisciplinar, Centro de Filosofia e Ciências Humanas, Universidade Federal de Santa Catarina, Florianópolis, 2003.

PELUSO JUNIOR, Victor. Aspectos Geográficos de Santa Catarina. Florianópolis: FCC/EDUFSC, 1990.

PERTILE, Noeli. Formação do Espaço Agroindustrial em Santa Catarina: O Processo de Produção de Carnes no Oeste Catarinense. 2008. 321 f. Tese (Doutorado em Geografia) Universidade Federal de Santa Catarina, Florianópolis-SC, 2008. 
SOUZA, Joel José de. O complexo de laticínios no Brasil: o caso da região Sul. 2014. 289 f. Tese (Doutorado) - Curso de Geografia, Geociências, Universidade Federal de Santa Catarina, Florianópolis, 2014.

\section{NOTAS DE AUTOR}

\section{CONTRIBUIÇÃO DE AUTORIA}

Eduardo von Dentz - Concepção. Coleta de dados, Análise de dados, Elaboração do manuscrito, revisão e aprovação da versão final do trabalho.

Carlos José Espíndola - Concepção e elaboração do manuscrito, Participação ativa da discussão dos resultados.

\section{FINANCIAMENTO}

Apoio na forma de bolsa e taxa de bancada, em nível de doutorado, do Conselho Nacional de Desenvolvimento Científico e Tecnológico - CNPq.

\section{CONSENTIMENTO DE USO DE IMAGEM}

Não se aplica.

\section{APROVAÇÃO DE COMITÊ DE ÉTICA EM PESQUISA}

Não se aplica.

\section{CONFLITO DE INTERESSES}

Não se aplica.

\section{LICENÇA DE USO}

Este artigo está licenciado sob a Licença Creative Commons CC-BY. Com essa licença você pode compartilhar, adaptar, criar para qualquer fim, desde que atribua a autoria da obra.

\section{HISTÓRICO}

Recebido em: 26-12-2018

Aprovado em: 04-02-2019 